УДК 378.14

«Сквозная» экологическая компетенция учителя как результат образования для устойчивого развития

\author{
Л. Е. Халудорова \\ Бурятский республиканский институт образовательной политики, \\ 2. Улан-Удэ
}

Аннотация. Введение. Актуальность проблемы формирования «сквозной» экологической компетенции учителей разных предметов обусловлена глобальными вызовами времени, современным состоянием развития образования. Цель исследования заключается в обосновании необходимости формирования «сквозной» экологической компетенции учителей разных предметов.

Материалы и методы. В статье рассматриваются теоретические основы феномена «сквозной» экологической компетениии учителя, обосновывается самостоятельность данной компетенции. Экспериментальным путём доказана эффективность формирования «сквозной» экологической компетенции учителя. Использовались такие методы, как анкетирование, «Вопросы самому себе», монографическая характеристика.

Результаты исследования. В результате анализа эмпирического материала сделан вывод о том, что большинство учителей не владеет в достаточной мере знаниями и навыками, связанными с вопросами образования для устойчивого развития. Это обусловлено с тем, что экологическая компетенция учителя рассматривается независимо, отдельно от его профессиональныхх компетениий. По этой причине необходимо конструирование такой экологической компетенции учителя, которая может способствовать решению им мировоззренческих, методологических и иенностно-смысловых задач самоопределения, саморазвития, самоактуализации в обществе в интересах устойчивого развития. Экспериментальным путём доказана целесообразность введения понятия «сквозная» экологическая компетенция» в педагогический тезаурус.

Заключение. Практическая значимость исследования заключается в совершенствовании экологической компетенции учителей разных предметов.

\section{Ключевые}

слова:

Для

цитирования: Халудорова Л. Е. «Сквозная» экологическая компетенция учителя как результат образования для устойчивого развития // Педагогический ИМИДЖ. 2020. Т. 14. № 4 (49). C.658-668.

DOI: $10.32343 / 2409-5052-2020-14-4-658-668$ 
Дата поступления статьи в редакцию: 14 мая 2020 г.

\section{Введение}

В быстро меняющемся мире мы отмечаем глобальные вызовы, одной из острых проблем современности является также экологический кризис. Для выживания в этих условиях необходимы кардинальные решения в экономической, социальной сфере, в основе которых лежит модернизация системы образования. В Европейской стратегии (ЕЭК ООН, 2005 г.) по образованию для устойчивого развития сказано о том, что передача знаний и навыков сегодня не является актуальной, что необходимо формировать у молодёжи готовность жить в непредсказуемых, неопределённых условиях будущего мира. Глобальная программа действий в области Образования в интересах устойчивого развития (ОУР) (2014) ориентирована на формирование нового миропонимания, которое может быть выстроено благодаря образованию. Таким образом, учащиеся должны знать, что такое устойчивое образование, как решать проблемы устойчивого развития, как пропагандировать устойчивый образ жизни.

В России экологическое образование на всех его ступенях рассматривается как стратегический ориентир устойчивого развития страны, а формирование экологической культуры личности является одной из приоритетных задач. На сегодня реализуются основные направления программы «Основы государственной политики в области экологического развития России на период до 2030 года». В ней, по сути, сформулирован новый социальный заказ для системы образования, который направлен на подготовку человека к участию в преобразовании мира и его адекватному проявлению в ситуациях противоречия с условиями своего обитания.

В этой связи сейчас актуальны идеи сохранения жизни, поддержания её устойчивости, которые отражены в требованиях к условиям, результатам, содержанию образования в ФГОС ОО и содержательно раскрыты в Концепции общего экологического образования для устойчивого развития. В настоящее время экологическое образование рассматривается как образование в интересах устойчивого развития общества, для него характерна мировоззренческая, методологическая и аксиологическая направленность. А это, безусловно, способствует устойчивому социально-экономическому развитию общества, которое является экологически безопасным. Соответственно, необходима готовность учителей, их способность адекватно реагировать на запросы развивающейся экологически безопасной экономики, национальные интересы безопасности, вызовы государственной образовательной политики.

Вместе с тем сегодня учитель-практик в недостаточной степени ориентируется в этих неопределённых условиях. Он не задумывается над тем, что все учебные дисциплины в школе, а не только биология, химия и география, должны содержать в себе идею устойчивого развития (далее - УР) и реализовывать мировоззренческую миссию современного экологического образования. Экологические принципы должны проникнуть в образовательные организации, в различные сферы жизнеде- 
ятельности субъектов образования. Соответственно, экологическая компетентность должна носить «сквозной» характер, а не рассматриваться отдельно от профессиональных (ключевых, базовых, специальных) компетенций педагога. Для ответа на эти вызовы нами был поставлен вопрос о конструировании «сквозной» экологической компетенции учителя в условиях дополнительного профессионального образования. Но обозначенная проблематика является ещё не изученной, новой, на наш взгляд, перспективной областью научно-педагогических решений. В этой связи иелью написания статьи является обоснование необходимости формирования «сквозной» экологической компетенции учителей разных предметов. Для достижения этой цели необходимы следующие задачи: рассмотреть теоретические основы понятия «сквозная» экологическая компетенция, раскрыть методы его исследования и проанализировать полученные результаты.

\section{Теоретические основы феномена «сквозная» экологическая компетенция}

Теоретическими предпосылками для конструирования «сквозной» экологической компетенции учителя являются труды Н. Н. Моисеева (объективность «экологического императива») [17], Н. М. Мамедова (культура устойчивого развития как прогнозируемый результат образования для устойчивого развития) [15], А. Н. Захлебного (экологическое образование для устойчивого развития как инструмент порождения новых смыслов в содержании общего образования) [10], Е. Н. Дзятковской (транспредметная методическая система образования для устойчивого развития) [9], С. В. Алексеева (непрерывное экологическое образование педагога как необходимое условие эффективности системы развития экологической культуры молодёжи) [1], И. Н. Пономаревой (концептуальные положения и программы образования и воспитания) [19], Н. Ж. Дагбаевой (образование для устойчивого развития в Байкальском регионе) [7].

Изучению феномена компетенций посвящены работы Н. В. Кузьминой [13], А. К. Марковой [16] (компетентностный подход в психолого-педагогической науке); В. А. Болотова [3] (способность человека эффективно действовать за пределами учебных сюжетов и учебных ситуаций); Э. Ф. Зеера [11], И. А. Зимней [12], Дж. Равена [20], А. П. Тряпицыной [23], В. Д. Шадрикова [24] (компетенции в системе непрерывного образования); М. В. Аргуновой [2], Е. Н. Дзятковской [9], А. Н. Захлебного [10] (компетенции в условиях внедрения ФГОС ОО); С. Н. Глазачева [5], А. А. Вербицкого [4], Ю. М. Гришаевой [6], О. Г. Роговой [21] (компетенции в высшем образовании).

Ю. М. Гришаева отмечает, что под «экологической компетентностью учителя следует понимать его способность и готовность к эколого-педагогической деятельности, направленной на создание и поддержание эффективной экологической образовательной среды, способствующей повышению уровня экологической культуры всех участников педагогического взаимодействия» [6]. В этом контексте феномен экологической компетентности обсуждается независимо от профессиональной компетентности, узконаправленной. Так, появляется вопрос о необходимости в такой экологической компетенции, которая явилась бы «сквозной» в профессиональных компетенциях, тогда она должна конструироваться и рассматриваться не только как базовая, как отдельная, ключевая или специальная компетенция.

По этой причине более детального рассмотрения требует вводимое в педагогический тезаурус понятие «сквозная» компетенция», т. е. возникает вопрос о значении слова «сквозная».

А. М. Новиков, анализируя и сравнивая особенности общего и профессионального образования, отмечает, что между ними появляются такие образовательные компоненты, которые нельзя отнести ни к общему, ни к собственно профессиональному образованию. Эти компоненты важны в любой профессиональной деятельности. Их 
условно можно назвать «базисными квалификациями». Знания и умения, как работа на компьютерах, пользование базами и банками данных, знание и понимание экологии, экономики и бизнеса, финансовые знания, по-другому он называет «сквозными», и они действительно носят «сквозной» характер [18].

Любая подсистема содержания образования состоит из базисных компонентов и, как пишет В. С. Леднев, «входит в его общую структуру двояко: во-первых, в качестве “сквозной” линии по отношению к апикальным структурным компонентам, во-вторых ... в качестве одного из апикальных, явно выраженных компонентов» [14]. Он это называет «принципом «двойного вхождения». М. В. Рыжаков утверждает, что система общего образования имеет «сквозное» ценностно-мировоззренческое содержание [22]. Г. А. Ягодин рассматривал «сквозной» характер экологической компетенции [26]. П. Г. Щедровицкий подчёркивал, что «сквозная» компетенция - это «пронизывающая» компетенция. Это касается того, что существует как массовое, того, что есть у всех или у многих» [25]. По мнению Э. Ф. Зеера, «сквозные» компетенции - это такие компетенции, «которые присущи любой должности» [11].

Далее, в построении структуры «сквозной» экологической компетенции личности мы опирались на разные подходы учёных в сфере исследования компетенций. Они выделяют общепринятые, взаимосвязанные компоненты, которые ориентированы на формирование знаний, умений, навыков; ценностного отношения к природной среде; практической экологически направленной деятельности. К примеру, следующие: эколого-когнитивный, этически-социальный, профессионально-поведенческий [8]; методологический, мотивационно-ценностный, познавательно-информационный, прогностический компоненты [18]. Таким образом, сравнение с вариантами, предложенными выше, показывает, что эти компоненты почти адекватны. Отсюда появляется закономерный вопрос о добавлении экологического компонента в содержание профессиональных компетенций и возникает необходимость в экологизации всех компонентов профессиональных компетенций, «вплетая» в них экологическую составляющую как «сквозную функциональность» [9].

В контексте нашего исследования «сквозная» экологическая компетенция представляет собой совокупность взаимосвязанных экологических компонентов профессиональных (ключевых, базовых и специальных) компетенций и общекультурной компетенции учителя. Данное понятие обосновывается компетентностным, культурологическим и субъектным подходами.

Экологический компонент в профессиональных (ключевых, базовых, специальных) компетенциях учителя можно представить следующим образом (см. табл. 1).

Таблииа 1

Table 1

\begin{tabular}{|l|l|l|}
\hline № & $\begin{array}{c}\text { Профессиональные } \\
\text { компетенции }\end{array}$ & Экологический компонент профессиональных компе- \\
тенций
\end{tabular}




\begin{tabular}{|c|c|c|}
\hline 2 & Базовые & $\begin{array}{l}\text { Знание методов, приёмов, способов развёртывания экологи- } \\
\text { чески направленной деятельности, предоставление учащим- } \\
\text { ся возможностей для их самоопределения в профессиях, свя- } \\
\text { занных с экологией; умение разрабатывать образовательные } \\
\text { программы на разных уровнях, индивидуальные программы, } \\
\text { маршруты, связанные с овладением экологической культу- } \\
\text { рой; ответственное отношение к процессу и результатам } \\
\text { образования и воспитания экологической направленности; } \\
\text { опыт, связанный с изучением, исследованием особенностей } \\
\text { экологического образования в интересах устойчивого разв-- } \\
\text { тия }\end{array}$ \\
\hline 3 & Специальные & $\begin{array}{l}\text { Знание ФГОС ОО, отражение в нём экологически направ- } \\
\text { ленного аспекта и включение идей устойчивого развития в } \\
\text { школьные предметы; умение определять, выполнять общие } \\
\text { и учебные экологически направленные задачи на уроках и во } \\
\text { внеурочной, внеклассной, общешкольной деятельности для } \\
\text { формирования экологической культуры учителя и учащих- } \\
\text { ся; ответственное отношение к природе, людям, обществу; } \\
\text { опыт формирования у обучающихя экологически направ- } \\
\text { ленной активной познавательной деятельности }\end{array}$ \\
\hline
\end{tabular}

В состав рассматриваемой нами компетенции вошла общекультурная компетенция (табл. 2), так как в современном мире происходят глобальные изменения во всех сферах жизнедеятельности человека, общества, которые связаны с экологической безопасностью. Экологический аспект мы находим и в вопросах, связанных с международными отношениями, с национальным компонентом в интересах устойчивого развития и др.

Таблица 2

Table 2

\begin{tabular}{|c|c|c|}
\hline № & $\begin{array}{c}\text { Профессиональные } \\
\text { компетенции }\end{array}$ & $\begin{array}{c}\text { Экологический компонент } \\
\text { профессиональных компетенций }\end{array}$ \\
\hline 1. & Общекультурные & $\begin{array}{l}\text { Знание современной научной картины мира как основы } \\
\text { экологической культуры устойчивого развития; истории } \\
\text { развития экологической культуры; умение выявять эколо- } \\
\text { гические, социальные и экономические взаимосвязи в окру- } \\
\text { жающем мире; прошлого, настоящего и будущего; права и } \\
\text { морали; глобального и локального; работать в команде; про- } \\
\text { свещения; ценностное отношение к опыту экологической } \\
\text { культуры человечества, полиэтнокультурному наследию } \\
\text { гармоничного развития природы и общества, к экологиче- } \\
\text { ским традициям местного сообщества; приоритет ценности } \\
\text { жизни во всех проявлениях, качества окружающей среды, } \\
\text { личностные смыслы гражданского поведения на основе об- } \\
\text { щечеловеческих ценностей в системе «человек - общество } \\
\text { - природа»; опыт самоопределения в системе культурных } \\
\text { ценностей и смыслов для устойчивого развития, приобщения } \\
\text { к экологической культуре, патриотического и гражданского } \\
\text { воспитания }\end{array}$ \\
\hline
\end{tabular}

Однако, «сквозная» экологическая компетенция, представленная в этом виде, проявляет эмерджентные свойства. Все экологические компоненты компетенций позволяют в целом решать задачи самоидентификации, самоопределения, самоактуализации 
и, в конечном итоге, саморазвития учителя в смысловом поле многоплановых проблем экологического образования для устойчивого развития.

Структура «сквозной» экологической компетенции позволяет адекватно реагировать на все динамично меняющиеся мировоззренческие, методологические новообразования: формировать новое качество предметного содержания, соотносить педагогические теории с вызовами времени, развивать понятийно-терминологический аппарат, решать задачи понимания, объяснения, порождения смыслов и т. д.

«Сквозная» экологическая компетенция направлена на овладение педагогом готовностью к экологизации содержания всех направлений профессиональной деятельности в опережающем векторе. Применение «сквозной» экологической компетенции позволяет активно влиять на образовательную и эколого-культурную среду учреждения, влиять на деятельность других общественных институтов, коллективов и движений, гальванизировать процессы экологически устойчивого развития общества. «Сквозная» экологическая компетенция реализует мировоззрение устойчивого развития; выстраивается на экоцентрированном сознании, экологическом мышлении, культуре устойчивого развития, которые находятся в диалектической взаимосвязи.

Таким образом, «сквозная» экологическая компетенция понимается нами как совокупность взаимосвязанных экологических компонентов профессиональных и общекультурной компетенций учителей, объединённых общей предметно-деятельностной структурой и философско-научными основаниями концепции устойчивого развития, обеспечивающая способность и готовность учителей разных предметов опережающе ставить и решать мировоззренческие, методологические и ценностно-смысловые задачи профессиональной самореализации и саморазвития.

\section{Методы исследования}

Ключевую роль в исследовании выполняли такие методы, как педагогический эксперимент, наблюдение, сравнение и прогнозирование. Полученные результаты были проанализированы посредством анкетирования, метода «Вопросы самому себе» К. Роджерса, монографической характеристики. Мониторинг формирования «сквозной» экологической компетенции учителей был проведён на основе оценивания уровней сформированности её экологических компонентов в ключевых, базовых, специальных компетенциях и общекультурной экологической компетенции; её системности, отражающейся в самооценке, самоопределении и саморазвитии. Результаты сопоставления входной и итоговой диагностики «сквозной» экологической компетенции учителей выявили, что достоверные изменения отмечаются во всех экспериментальных группах, в отличие от контрольной.

\section{Результаты исследования}

Обобщённое и краткое сравнение продвижения обучающихся исследуемых экспериментальных и контрольной групп в освоении знаний, умений, отношений, опыта показало, что в экспериментальной группе 1 наиболее значимые результаты были достигнуты в знаниях слушателей, минимальный - в области освоения новых педагогических практик. В экспериментальной группе 2 деятельностный компонент результатов был выражен ещё меньше. Из значимых результатов было изменение уровня знаний и отношений. В экспериментальной группе 3 были получены наиболее высокие относительные и абсолютные результаты формирования знаний, умений, отношениий, опыта деятельности (табл. 3). 


\section{Сводная таблица результатов входной и итоговой диагностики по всем группам слушателей}

\begin{tabular}{|c|c|c|c|c|c|c|c|c|c|c|}
\hline Группы & \multicolumn{2}{|c|}{ Знания } & \multicolumn{2}{c|}{ Умения } & \multicolumn{2}{c|}{ Отношения } & \multicolumn{2}{c|}{ Опыт } & \multicolumn{2}{c|}{ В среднем } \\
\hline & вход & итог & вход & итог & вход & итог & вход & итог & вход & итог \\
\hline $\begin{array}{c}\text { Экспери- } \\
\text { менталь- } \\
\text { ная 1 }\end{array}$ & 3,1 & $4,4^{*}$ & 2,7 & $3,8^{*}$ & 2,9 & $4,0^{*}$ & 2,7 & $3,6^{* *}$ & 2,8 & $4,0^{*}$ \\
\hline $\begin{array}{c}\text { Экспери- } \\
\text { менталь- } \\
\text { ная 2 }\end{array}$ & 3,2 & $4,4^{*}$ & 2,9 & 3,4 & 3,1 & $3,8^{*}$ & 2,8 & 3,2 & 3,0 & $3,8^{*}$ \\
\hline $\begin{array}{c}\text { Экспери- } \\
\text { менталь- } \\
\text { ная 3 }\end{array}$ & 3,0 & $4,9^{*}$ & 2,8 & $4,8^{*}$ & 3,0 & $4,9^{*}$ & 2,8 & $4,3^{*}$ & 2,9 & $4,8^{*}$ \\
\hline $\begin{array}{c}\text { Кон- } \\
\text { трольная } \\
\text { группа }\end{array}$ & 3,3 & 3,6 & 2,9 & 2,8 & 3,2 & 3,0 & 2,8 & 3,2 & 3,0 & 3,3 \\
$* \quad \mathrm{p} \leq 0,01$ & $* * \mathrm{p} \leq 0,05$ & & & & & & \\
\hline
\end{tabular}

Было доказано, что обучение учителей с их погружением в природную и социокультурную среду региона повышает уровень сформированности «сквозной» экологической компетенции. У них развиваются рефлексивно-оценочные умения, которые способствуют их профессиональному и личностному росту. Такая компетенция будет востребованной и становится результатом образования в интересах устойчивого развития.

\section{Заключение}

При обобщении нельзя считать, что все учителя без исключения являются настолько компетентными и не только могут влиять на учеников, родителей, местное сообщество (общекультурная экологическая компетенция), но и самостоятельно, сознательно работать над развитием своих компетенций («сквозная» экологическая компетенция). В связи с этим появляется необходимость расширения круга педагогических сообществ для реализации идей устойчивого развития - создания критической массы учителей носителей идей устойчивого развития - для «пропитки» в такой среде всех, кто в ней находится, чтобы каждый учитель проникся этими идеями, для этого ему нужно, прежде всего, хорошо представлять смысл и ценность этих идей. Необходимо изменение профессионального мышления учителей и их мировоззрения для принятия, освоения и присвоения идей и принципов образования в интересах устойчивого развития. Говоря о перспективных направлениях экологизации содержания дополнительного профессионального образования учителей, мы считаем необходимым ещё раз актуализировать вопросы, связанные с основными смыслами и ценностями устойчивого развития.

\section{Автор прочитал и одобрил окончательный вариант рукописи.}

\section{Список литературы}

1. Алексеев С. В. Непрерывное экологическое образование педагога - необходимое условие эффективности системы развития экологической культуры молодежи // Эколо- 
гическое образование: до школы, в школе, вне школы. 2014. № 3. С. 10 -13

2. Аргунова М. В. Экологическое образование в интересах устойчивого развития как надпредметное направление модернизации школьного образования : автореф. дис. ... д-ра пед. наук: 13.00.02. М., 2010. 48 с.

3. Болотов В. А., Сериков В. В. Компетентностная модель: от идеи к образовательной программе // Педагогика. 2003. № 10. С. 8-14.

4. Вербицкий А. А., Ларионова О. Г. Личностный и компетентностный подходы в образовании. Проблемы интеграции. М. : Логос, 2009. 336 с.

5. Глазачев С. Н. Глобальные вызовы современности и миссия образования. [Электронный ресурс] // Вестник Международной академии наук. Русская секция. 2010. № 1. C. 28-32 URL: https://cyberleninka.ru/article/n/metodologicheskie-dialogi-kak-sredstvorazvitiya-ekologicheskoy-kultury-lichnosti (дата обращения: 09.05.2016).

6. Гришаева Ю. М. Концепция формирования эколого-профессиональной компетентности студентов гуманитарного вуза : дис. ... д-ра пед. наук : 13.00.08. М. : 2014. $372 \mathrm{c}$.

7. Дагбаева Н. Ж. Экологическое образование школьников в условиях изменения социоприродной среды : дис. ... д-ра пед. наук : 13.00.01. Улан-Удэ, 2004. 385 с.

8. Даниленкова В. А. Формирование экологической компетенции у студентов технического вуза : дис. ... канд. пед. наук : 13.00.08. Калининград, 2005.122 с.

9. Дзятковская Е. Н. Образование для устойчивого развития в школе. Культурный концепт. «Зеленая аксиома». Трансдисциплинарность. М. : Образование и экология, 2015. $328 \mathrm{c}$.

10. Захлебный А. Н., Дзятковская Е. Н. Результаты и перспективы совершенствования образования в интересах устойчивого развития в системе общего образования [Электронный ресурс] // Экологическое образование: до школы, в школе, вне школы. 2016. № 1. C. 1-4 http://partner-unitwin.net/wp-content/uploads/2016/06/перспективы-OYP.pdf (дата обращения: 23.10.2019).

11. Зеер Э Ф. Основные смыслообразующие положения личностно-развивающего образования // Образование и наука. 2006. № 5 (4). С. 3-12.

12. Зимняя И. А. Ключевые компетентности как результативно-целевая основа компетентностного подхода в образовании. М. : ИЦПКПС, 2004. 42 с.

13. Кузьмина Н. В. Профессионализм личности преподавателя и мастера производственного обучения. М. : Высшая школа, 1990. 9119 с.

14. Леднев В. С. Содержание образования: сущность, структура, перспективы. М. : Высшая школа, 1991. 186 с.

15. Мамедов Н. М. Экологическая концепция культуры: философско-методологические основания // Вестник экологического образования в России. № 2. 2016. С. 1-5.

16. Маркова А. К. Психология труда учителя: книга для учителя. М. : Просвещение, 1993. $192 \mathrm{c}$.

17. Моисеев Н. Н. Современный антропогенез и цивилизационные разломы. Эколого-политологический анализ // Вопросы философии. 1995. № 1. С. 3-30.

18. Новиков А. М., Новиков Д. А. Методология. М. : СИНТЕГ, 2007. 668 с.

19. Пономарева И. Н. Основные концептуальные положения и программы экологического образования и воспитания // Проблемы экообразования в школе и педвузе: материалы тезисов междунар. конф. по методике преподавания биологии. - СПб. : 1993. C. $4-86$.

20. Равен Д. Компетентность в современном обществе: выявление, развитие и реализация ; пер. с англ. М. : Когито-Центр, 2002. 396 с.

21. Роговая О. Г. Становление эколого-педагогической компетентности специалиста в области образования : дис. ... д-ра пед. наук : 13.00.08. СПб., 2008. 395 с.

22. Рыжаков М. В. Теоретические основы разработки государственного стандарта 
общего среднего образования : дис. ... д-ра пед. наук : 13.00.01. М. : 1999. 371 с.

23. Тряпицына, А. П., Писарева С. А. Современные методологические подходы к исследованию педагогического образования // Академический вестник Института пед. образ. взрослых РАО. Человек и образование. 2014. № 3 (40). С. 7.

24. Шадриков В. Д. Психология деятельности и способности человека. М. : Логос. $1996.320 \mathrm{c.}$

25. Щедровицкий Г. П. Избранные труды / ред.-сост: А. А. Пископпель, Л. П. Щедровицкий. М. : Школа культурной политики, 1995. 800 с.

26. Ягодин Г. А. Экология и устойчивое развитие в системе образования // Экологическое образование: до школы, в школе, вне школы. 2003. № 4. С. 3-7.

\section{References}

1. Alekseev S. V. Nepreryvnoe ekologicheskoe obrazovanie pedagoga - neobkhodimoe uslovie effektivnosti sistemy razvitiya ekologicheskoy kul'tury molodezhi [Continuous environmental education of a teacher is a necessary condition for the effectiveness of the system for the development of environmental culture of youth], Ekologicheskoe obrazovanie: do shkoly, v shkole, vne shkoly, 2014, no. 3, pp. 10-13.

2. Argunova M.V. Ehkologicheskoe obrazovanie v interesakh ustoichivogo razvitiya kak nadpredmetnoe napravlenie modernizatsii shkol'nogo obrazovaniya [Environmental education in the interests of sustainable development as a subject area of modernization of school education]: avtoreferat dis. na soiskanie uchenoi stepeni d-ra ped. nauk: 13.00.01/. M.: [b.i.], 2009. 44 p. (in Russian)

3. Bolotov V.A. Kompetentnostnaya model': ot idei k obrazovatel'noi programme [Competency Model: From Idea to Educational Program]. Pedagogika. 2003. no. 10. P. 8-14. (in Russian)

4. Verbitskii A.A. Lichnostnyi i kompetentnostnyi podkhody v obrazovanii [Personal and competency-based approaches in education]. Logos, 2009. 106 p. (in Russian)

5. Glazachev S.N. Global'nye vyzovy sovremennosti i missiya obrazovaniya [Global challenges of modernity and education mission]. URL: http://www.ecogeo.info/publications/8/. Zagl. s ehkrana (data of access: 09.05.2016). (in Russian)

6. Grishaeva Yu.M. Kontseptsiya formirovaniya ehkologo-professional'noi kompetentnosti studentov gumanitarnogo vuza [The concept of the formation of environmental and professional competence of humanitarian students]: dis. na soiskanie uchenoi stepeni d-ra ped. nauk: 13.00.08. M.: 2014. 372 p. (in Russian)

7. Dagbaeva N.Zh. Ehkologicheskoe obrazovanie shkol'nikov v izmenyayushchikhsya sotsioprirodnykh usloviyakh [Environmental education of schoolchildren in changing social and natural conditions]: dis. na soiskanie uchenoi stepeni d-ra ped. nauk: 13.00.01. UlanUde, 2004. 385 p. (in Russian)

8. Danilenkova V.A. Formirovanie ehkologicheskoi kompetentsii u studentov tekhnicheskogo vuza [The formation of environmental competence among students of a technical university]: dis. na soiskanie uchenoi stepeni kand. ped. nauk: 13.00.08 / Kaliningrad, 2005. 122 p. (in Russian)

9. Dzyatkovskaya E.N. Obrazovanie dlya ustoichivogo razvitiya v shkole. Kul'turnye kontsepty. «Zelenye aksiomY». Transdistsiplinarnost' [Education for sustainable development at school. Cultural concepts. "Green axioms." Transdisciplinarity]. Obrazovanie i ehkologiya, 2015. 360 p. (in Russian)

10. Zakhlebnyi A.N. Rezul'taty i perspektivy sovershenstvovaniya obrazovaniya v interesakh ustoichivogo razvitiya $\mathrm{v}$ obshchem obrazovanii [Results and prospects of improving education for sustainable development in general education]. Ehkologicheskoe obrazovanie: do shkoly, v shkole, vne shkoly. 2016. no. 1. P. 14-16. (in Russian) 
11. Zeer, R.F. Osnovnye smysloobrazuyushchie polozheniya lichnostno-razvivayushchego obrazovaniya [The basic meaning-forming provisions of personality-developing education]. Obrazovanie i nauka: Izvestiya Ural'skogo otd. RAO. 2006. no. 5. pp. 3-15. (in Russian)

12. Zimnyaya I.A. Klyuchevye kompetentnosti kak rezul'tativno-tselevaya osnova kompetentnostnogo podkhoda $\mathrm{v}$ obrazovanii [Key competencies as an effective and targeted basis of the competency-based approach in education]. ITSPKPS, 2004. 42 p. (in Russian)

13. Kuz'mina N.V. Professionalizm lichnosti prepodavatelya i mastera proizvodstvennogo obucheniya [Professionalism of the personality of the teacher and master of vocational training]. Vysshaya shkola, 1990. 90 p. (in Russian)

14. Lednev V.S. Soderzhanie obrazovaniya [Educational content]. Prosveshchenie, 1991. 186 p. (in Russian)

15. Mamedov N.M. Ehkologicheskaya kontseptsiya kul'tury: filosofsko-metodologicheskie osnovaniya [The ecological concept of culture: philosophical and methodological foundations]. Vestnik ehkologicheskogo obrazovaniya v Rossii. no. 2(80). 2016. pp. 1-5. (in Russian)

16. Markova A.K. Psikhologiya truda uchitelya [Tekst]: [Kniga dlya uchitelya] [Psychology of teacher work [Text]: [Book for the teacher]. Prosveshchenie, 1993. 192 p. (in Russian)

17. Moiseev N.N. Sovremennyi antropogenez i tsivilizatsionnye razlomy. Ehkologo-politologicheskii analiz [Modern anthropogenesis and civilizational faults. Ecological and political science analysis]. Voprosy filosofii. 1995 no. 1. P. 4. (in Russian)

18. Novikov A.M. Metodologiya [Methodology]. 2007. 668 p. (in Russian)

19. Ponomareva I. N. Osnovnye kontseptual'nye polozheniya i programmy ekologicheskogo obrazovaniya i vospitaniya [Basic conceptual provisions and programs of environmental education and upbringing], Problemy ekoobrazovaniya v shkole i pedvuze: materialy tezisov mezhdunarodnoy konferentsii po metodike prepodavaniya biologii, Sankt-Peterburg: Obrazovanie, 1993, pp. 84-86.

20. Raven D. Kompetentnost' v sovremennom obshchestve [Tekst]: vyyavlenie, razvitie i realizatsiya [Competence in modern society [Text]: identification, development and implementation]. [Per. s angl.], Kogito-Tsentr, 2002. 394 p. (in Russian)

21. Rogovaya O.G. Stanovlenie ehkologo-pedagogicheskoi kompetentnosti spetsialista $\mathrm{v}$ oblasti obrazovaniya [Formation of ecological and pedagogical competence of a specialist in the field of education]: dis. d-ra ped. nauk: spets. 13.00.08. SPb. 2008. 395 p. (in Russian)

22. Ryzhakov M.V. Teoreticheskie osnovy razrabotki gosudarstvennogo standarta obshchego srednego obrazovaniya [The theoretical basis for the development of the state standard for secondary education]: dis. d-ra ped. nauk: 13.00.01. M.: 1999. 371 p. (in Russian)

23. Tryapitsyna A.P. Sovremennye metodologicheskie podkhody $\mathrm{k}$ issledovaniyu pedagogicheskogo obrazovaniya [Modern methodological approaches to the study of teacher education]. Akademicheskii vestnik Instituta ped. obraz. vzroslykh RAO. Chelovek i obrazovanie. 2014. no. 3 (40). P. 7. (in Russian).

24. Shadrikov V.D. Psikhologiya deyatel'nosti i sposobnosti cheloveka [Psychology of human activity and ability]. Izdatel'skaya korporatsiya «LogoS». 1996. 320 p. (in Russian)

25. Shchedrovitskii G.P. Izbrannye trudy. Selectedworks / G. P. Shchedrovitskii; [red.sost: A. A. Piskoppel', L. P. Shchedrovitskii; vstup. st. A. Piskoppelya]. Izd-vo shkoly kul'turnoi politiki, 1995. 759 p. (in Russian).

26. Yagodin G.A. Ehkologiya i ustoichivoe razvitie v sisteme obrazovaniya [Ecology and sustainable development in the education system]. Ehkologicheskoe obrazovanie: do shkoly, v shkole, vne shkoly. 2003. no. 4. pp. 3-7. (in Russian). 


\title{
Transversal Environmental Competence of Teacher as a Result of Education for Sustainable Development
}

\section{Liubov E. Khaludorova}

Buryat Republican Institute of Educational Policy, Ulan-Ude

\begin{abstract}
Introduction. The relevance of developing a transversal environmental competence in teachers of various subjects is determined by the global challenges of the time, and the current state of educational development. The study aims to justify the need to form the transversal environmental competence in teachers of different subjects.

Materials and methods. The paper discusses theoretical foundations of the phenomenon of transversal environmental competence of the teacher, and substantiates the independence of this competency. Experiments have been made to prove the effectiveness of the development of a transversal environmental competence in the teacher. The methods employed in the study also included questionnaires "Questions to yourself," and a monographic description.

The results of the study. An analysis of empirical material concluded that most teachers do not have sufficient knowledge and skills related to the issues of education to promote sustainable development. This is due to the fact that the environmental competence of the teacher is considered separately from their professional competencies. Therefore, it is necessary to build such environmental competence of teachers, which can help them solve worldview, methodological and axiological problems of self-identification, self-determination, self-actualization, and self-development in a society in the interests of sustainable development. In this regard, the appropriateness of introducing the concept of a "transversal environmental competence" in the pedagogical thesaurus has been experimentally proved.

Conclusion. The practical value of the study lies in the improvement of the environmental competence in teachers of various subjects.
\end{abstract}

Keywords: professional competence, transversal environmental competence, environmental education, construction, sustainable development.

\section{Любовь Енжаповна Халудорова}

доктор педагогических наук, доцент

кафедры гуманитарных дисичиплин

ORCID https://orcid.org/

0000-0003-4527-7460

Бурятский республиканский институт образовательной политики

670000, Россия, Улан-Удэ,

ул. Советская, 30

тел.: +7 (3012) 211361

e-mail: l.e.khaludorova@mail.ru

\section{Liubov E. Khaludorova}

Doctor of Sciences (Pedagogy), Associate Professor of Department of the Humanities

ORCID https://orcid.org/

0000-0003-4527-7460

Buryat Republican Institute of Educational Policy

30 Sovetskaya St, Ulan-Ude, Russia, 670000

tel.: +7 (3012) 211361

e-mail:l.e.khaludorova@mail.ru 